\title{
John Ribchester: pioneering in general practice
}

\author{
The GP surgeon, who has championed new care models speaks to Kathy Oxtoby
}

\author{
Kathy Oxtoby
}

\section{The best choice}

When I was 14 years old, I decided that being a doctor was the only career for me. I was keen on sciences and both my parents were physics graduates, but my favourite science was biology. A career in medicine seemed the best possible choice. I didn't have a plan B.

\section{Specialty choice}

Initially I trained in surgery, but switched to general practice as I wanted a career that offered more continuity of patient care and a more holistic approach. I realised the idea of caring for people and families, rather than referring to patients as "hernia in bed one" or "gallbladder in bed two," was more satisfying.

\section{The GP surgeon}

I decided to combine surgical and general practice skills, and when I joined Whitstable Medical Practice in 1979 there was an operating theatre in a community hospital. For about 12 years, twice a week, I carried out operations in three

disciplines-general surgery, gynaecology, and orthopaedics. I've also run a sports injury clinic for a number of years.

\section{Bridging the divide}

The opportunity to use my hospital acquired skills in a community setting got me interested in the idea of integrated healthcare, as opposed to primary and secondary care where "never the twain shall meet"-which is sadly the situation for most doctors. That interest has become a lifelong passion.

\section{Growing a practice}

Since 1995 I've been executive and managing partner for Whitstable Medical Practice. During this time the practice has grown from a single site, 12 GP partnership to an integrated general practice at scale with 23 GPs, nearly 200 staff, and 40 000 patients served from four sites.

\section{From the heart}

Our practice is the "hub" at the heart of a primary care network. We provide list based general practice to the entire population of Whitstable, alongside a range of healthcare services that would otherwise require a trip to hospital. These can be accessed by patients from a wider area and include diagnostics, outpatients and procedures, screening services, and day surgery.

\section{Building new models}

One of my career highlights has been leading a new model of care-the Encompass Multispecialty Community Provider. Our initiatives have provided a better patient experience, better health outcomes, and both clinical and financial economies. Our challenge now is to help roll out the care model throughout Kent, which has a patient population of over 1.8 million.

\section{On receiving an $M B E$}

In 2018 I was awarded an MBE in the Queen's birthday honours list for services to general practice, which I received in front of my family. It was an exciting and humbling experience. But as far as I was concerned the award was for everybody's work in our team.

\section{Next generation}

I've been invited to join the development board for the Kent and Medway Medical School which opens in 2020. This includes the ambition for the practice to become a medical student community learning hub.

\section{Future ambitions}

I don't have any plans to retire yet but I imagine I'll wind down a bit. I want to carry on working part time at least until I'm 70 . All the time I'm trying to change and improve models of health and social care. I feel I'm making some progress, and making a difference. It's worthwhile work - and I don't think I've finished yet. 


\section{Career timeline}

1979-present GP, executive partner, Whitstable Medical Practice, Whitstable

2015-2018 Chair and clinical lead of the Encompass Multispecialty Community Provider vanguard

2006-2012 GP with a special interest for surgery in primary care and also carpal tunnel decompression surgery

July 2007-September 2008 Medical manager of the Canterbury and

Coastal Commissioning Consortium

2001-2005 GP adviser to the Department of Health

1975-1979 King's College, London 